\title{
Impact of fatty acid composition on the accuracy of mid-infrared fat analysis of farm milks ${ }^{1}$
}

\author{
K. E. Kaylegian, ${ }^{*}$ D. A. Dwyer,† J. M. Lynch, ${ }^{*}$ D. E. Bauman,† J. R. Fleming,ł and D. M. Barbano*² \\ ${ }^{*}$ Northeast Dairy Foods Research Center, Department of Food Science, and \\ †Department of Animal Science, Cornell University, Ithaca, NY 14853 \\ fUSDA, Agricultural Marketing Service Southwest Milk Marketing Area, PO Box 110939, Carrollton, TX 75011
}

\section{ABSTRACT}

Our objective was to determine whether data from a previous study using model milk emulsions to characterize the influence of variation in fatty acid chain length and unsaturation on mid-infrared (MIR) fat predictions could be used to identify a strategy to improve the accuracy of MIR fat predictions on a population of farm milks with a wide variation in fatty acid chain length and unsaturation. The mean fatty acid chain length for 45 farm milks was 14.417 carbons, and the mean unsaturation was 0.337 double bonds per fatty acid. The range of fatty acid chain lengths across the 45 farm milks was 1.23 carbons, and the range in unsaturation was 0.167 double bonds per fatty acid. Fat B (absorbance by the carbon-hydrogen stretch) MIR predictions increased and fat A MIR (absorbance by the ester carbonyl stretch) predictions decreased relative to reference chemistry with increasing fatty acid chain length. When the fat B MIR fat predictions were corrected for sample-to-sample variation in unsaturation, the positive correlation between fat $\mathrm{B}$ and fatty acid chain length increased from a coefficient of determination of 0.42 to 0.89 . A $45: 55$ ratio of fat $\mathrm{B}$ corrected for unsaturation and fat A gave a smaller standard deviation of the difference between MIR prediction and reference chemistry than any ratio of the fat $B$ (without correction for unsaturation) and fat $\mathrm{A}$ or either fat $\mathrm{B}$ or fat A alone. This demonstrates the technical feasibility of this approach to improve MIR testing accuracy for fat, if a simple procedure could be developed to determine the unsaturation of fat in milk rapidly and to correct the fat $\mathrm{B}$ reading for the effect of unsaturation before being combined with fat $\mathrm{A}$.

\footnotetext{
Received November 18, 2008.

Accepted January 8, 2009.

${ }^{1}$ Use of names, names of ingredients, and identification of specific models of equipment is for scientific clarity and does not constitute any endorsement of product by authors, Cornell University, or the Northeast Dairy Foods Research Center.

${ }^{2}$ Corresponding author: dmb37@cornell.edu
}

Key words: infrared milk analysis, fatty acid composition

\section{INTRODUCTION}

In mid-infrared (MIR) milk analysis, fat has historically been measured using the absorbance of infrared light at the fat B wavelength $(3.48 \mu \mathrm{m}$; $\mathrm{C}-\mathrm{H}$ stretch $)$ and the fat $\mathrm{A}$ wavelength $(5.73 \mu \mathrm{m} ; \mathrm{C}=\mathrm{O}$ stretch $)$. The fat A measurement cannot compensate for variation among milks in fatty acid chain length and assumes that fat in all milks has the same chain length (Biggs and McKenna, 1989). The fat B measurement compensates for differences in fatty acid chain length (Biggs and McKenna, 1989), but assumes that the fat in all milks has the same amount of unsaturation. Variation among milks in unsaturation of fat will cause errors in the fat B prediction of milk fat. Variation in fatty acid composition of milk fat from farm to farm is created by differences in feeding practices. In general, feeding strategies that increase the fat content of the diet of the cow will cause changes in fatty acid composition, particularly if the fat is able to bypass hydrogenation in the rumen.

It is well documented that when the fatty acid chain length in milk fat increased, values for fat A are lower than with reference chemistry because the fat A measurement responds to the number of ester linkages (Dunkley et al., 1977; Franke et al., 1977; Stegeman et al., 1991). Kaylegian et al. (2009) reported that increasing the chain length increased the difference (i.e., MIR minus reference chemistry) between the MIR fat B prediction and reference chemistry by $0.0429 \%$ and the fat A prediction by $-0.0566 \%$ fat per unit increase in carbon number per $1 \%$ fat. Increasing unsaturation decreased the difference (i.e., MIR minus reference chemistry) between the MIR prediction of fat and reference chemistry for fat B by $-0.4021 \%$ and increased fat A by $0.0291 \%$ fat per unit increase in double bonds per 1\% fat (Kaylegian et al., 2009). Clearly, both chain length and unsaturation have a large influence on fat $\mathrm{B}$, but separately, changes in unsaturation and chain 
length cause the fat B and fat A MIR fat predictions to deviate from reference chemistry in opposite directions.

Milks from individual farms can be sorted by the magnitude of the difference (both positive and negative) between the MIR fat B and fat A readings. Divergence of fat $\mathrm{B}$ and fat $\mathrm{A}$ readings on an unknown sample indicates that the unknown milk being tested contains fat that differs from the mean chain length and unsaturation of the fat in the calibration milks used to adjust the secondary slope and intercept. Therefore, milks that have more divergence between MIR fat B and fat A predictions are likely to have a fatty acid composition that differs significantly from the mean fatty acid composition of the milk used to calibrate that instrument. Our practical experience in routine testing of large numbers of samples in multiple laboratories within the USDA Federal Milk Markets is that every instrument calibrated with the same milks that has intercorrection factors controlled by the same system of samples will have the same differences between fat $B$ and fat $A$ readings on the same unknown milks (data not shown).

Biggs and McKenna (1989) concluded that a $73: 27$ ratio of fat $B$ and fat $A$ gave better agreement with reference chemistry than either fat B or fat A. Biggs and McKenna (1989) justified this ratio based on the explanation that triglycerides in milk are approximately $27 \%$ by weight glycerol and $73 \%$ by weight fatty acids. This explanation is not correct. Glycerol as a percentage of the molecular weight of a milk fat trigylceride with a mean fatty acid chain length of 14.5 carbons and a mean unsaturation of 0.33 double bonds per fatty acid is approximately $11 \%$, not $27 \%$. However, it remains that Biggs and McKenna (1989) found that the 73:27 ratio gave a lower standard deviation of the difference (SDD) between reference chemistry and MIR-predicted chemistry than either fat B or fat A alone. Our objective was to determine whether data from a previous study using model milk emulsions to characterize the influence of variation in fatty acid chain length and unsaturation on MIR fat predictions could be used to identify a strategy to improve the accuracy of MIR fat predictions on a population of farm milks with a wide variation in fatty acid chain length and unsaturation.

\section{MATERIALS AND METHODS}

\section{Experimental Design}

Milks were obtained from individual farms from 3 different areas of the United States (New York, Texas, and Vermont) during the summer of 2005. Our goal was to select a group of farms with milks having a wide range of fatty acid chain length and unsaturation. Milks were tested for fat, true protein, and anhydrous lactose with a Fourier transform (FT) MIR milk analyzer with the fat $\mathrm{A}$, fat $\mathrm{B}$, protein, and lactose using the optimized virtual filter wavelengths reported previously (Kaylegian et al., 2009). The differences in MIR fat predictions (i.e., fat $\mathrm{B}$ minus fat $\mathrm{A}$ ) were used as the basis for selection of farms. Milks that have a fatty acid chain length and unsaturation similar to the milks used to calibrate the instrument will have fat B and fat A predictions that agree. The more the fatty acid chain length and unsaturation of milk differs from that of the calibration milks, the larger will be the difference between the MIR fat B and fat A predictions. The observed differences between fat B and fat A can be either positive or negative. The USDA Federal Milk Market Laboratories selecting the milks were asked to provide milks that had as wide a range of fat $\mathrm{B}$ minus fat A values as possible.

The farm milks were analyzed by chemical methods for fat, true protein, lactose, FFA content, and fatty acid composition. The mean fatty acid chain length and unsaturation for each milk were calculated from the fatty acid composition. The variation in MIR fat B and fat A predictions for the farm milks that was due to fatty acid chain length and unsaturation was compared with data reported for a model system (pure monoacid triglycerides and pasteurized skim milk) in which the chain length and unsaturation were varied systematically (Kaylegian et al., 2009). Approaches to improve the accuracy of MIR fat prediction using calculations to compensate for variation in fatty acid chain length and unsaturation were evaluated based on the data from 45 farms.

\section{Source of Farm Milk}

Milks were chosen from farms (by 3 USDA Federal Milk Market Laboratories) that were known to have a large difference between the MIR fat A and fat B readings. Milks obtained from farms in New York $(\mathrm{n}=$ $8)$, Texas $(n=27)$, and Vermont $(n=10)$ were packed in wet ice and shipped overnight to Cornell University for analysis.

\section{Chemical Analyses}

Chemistry values for each milk were determined using AOAC (2000) methods for fat by modified Mojonnier ether extraction (method 989.05; chapter 33.2.26), true protein by Kjeldahl nitrogen analysis (method 991.22; chapter 33.2.13), and lactose by enzymatic analysis (method 2006.06, 33.3.67). The FFA content was determined using a modified copper soap method (expressed as mEq of FFA/kg of milk; Ma et al., 2003). 


\section{Fatty Acid Composition}

The fatty acid composition of each farm milk was determined in duplicate using the method described by Lynch et al. (2005). An example of the calculation to convert the GLC data from a fatty acid methyl ester (FAME) basis to a fatty acid basis and the calculation of the mean chain length and unsaturation are shown in Table 1. The calculation began with the relative area percentage of GLC output on a FAME basis. A butter oil reference standard (CRM164, Commission of the European Communities, Community Bureau of Reference, Brussels, Belgium) was analyzed under the same conditions as the milk fat from the farm milks to obtain the GLC area percentage for the standard. The ratio of the GLC area percentage divided by the known weight percentage of the standard was used to calculate a recovery factor for each FAME. These recovery factors were multiplied by the GLC FAME area percentage to calculate the recovery corrected percentage FAME for each fatty acid. The individual recovery adjusted FAME were normalized to a sum of $100 \%$ for the known FAME in each sample. The adjusted FAME data were converted to a fatty acid basis by multiplying by a correction factor (molecular weight of each fatty acid divided by the molecular weight of its FAME) to remove the molecular weight of the methyl ester group for each fatty acid, and were then normalized to a sum of $100 \%$ to obtain the relative fatty acid composition based on the fatty acids not FAME. The relative fatty acid composition was used to calculate the mean fatty acid chain length and unsaturation by converting each fatty acid to a millimolar basis and weighting each fatty acid by multiplying by either the number of carbons or the number of double bonds in the fatty acid chain, respectively. The mean fatty acid chain length was calculated (Table 1) by dividing the total fatty acid concentration weighted for carbon number (i.e., 6,177.071 $\mathrm{mmol}$ ) by the total fatty acid concentration (i.e., $426.053 \mathrm{mmol}$ ). The mean unsaturation was calculated by dividing the total fatty acid concentration weighted for the number of double bonds (i.e., $139.351 \mathrm{mmol}$ ) by the total fatty acid concentration (i.e., $426.053 \mathrm{mmol}$ ).

\section{MIR Analyses}

Fourier transform MIR milk analyses were performed with a LactoScope FT infrared (FTIR) milk analyzer (Delta Instruments, Drachten, the Netherlands) by using a fixed-filter calibration approach. The virtual filter sample and reference center wavelengths and bandwidths used for fat $\mathrm{B}$, fat $\mathrm{A}$, protein, and lactose were optimized in a previous study (Kaylegian et al., 2009). Sample center wavelengths used for fat B, fat A, protein, and lactose were $3.508,5.721,6.489$, and $9.542 \mu \mathrm{m}$, and the reference wavelengths were $3.556,5.583,6.707$, and $7.734 \mu \mathrm{m}$, respectively (Kaylegian et al., 2009). The LactoScope FTIR was equipped with the FTIRScope and DataScope software from Delta Instruments, and the IR-QC software (Lynch et al., 2006; Kaylegian et al., 2009) developed at Cornell University. The LactoScope FTIR was set to a resolution of $8 \mathrm{~cm}^{-1}$ and a scan rate of 8 scans per analysis. The LactoScope was precalibrated according to the procedures described by Lynch et al. (2006), and was calibrated with modified milks (Kaylegian et al., 2006) on the day the farm milks were analyzed. The corrected readings were calculated using the calibration equations described by Kaylegian et al. (2006) and the intercorrection factors determined in a previous study (Kaylegian et al., 2009).

\section{Statistical Analyses}

All regression analyses were performed using the PROC REG function in SAS (version 8e, SAS Inst. Inc., Cary, NC). A regression analysis was performed to determine whether there was a correlation between fatty acid chain length and unsaturation, between reference chemistry fat, true protein, or lactose of the milks and the fatty acid chain length or unsaturation, between the FFA content of the milk and MIR-predicted fat (B and $\mathrm{A}$ ) or protein, and between fat $\mathrm{B}$ minus ether, fat $\mathrm{A}$ minus ether, or fat $\mathrm{B}$ minus fat $\mathrm{A}$ and fatty acid chain length.

\section{RESULTS AND DISCUSSION}

\section{Composition of Farm Milk-Chemical Analysis}

The fatty acid composition for farm milks from New York, Texas, and Vermont with the minimum and maximum fatty acid chain length and unsaturation are shown in Table 2. In all 3 states, the milk with the shortest fatty acid chain length also had the smallest number of double bonds per fatty acid (Table 2). It is interesting to note that in New York and Vermont, the milk with the longest fatty acid chain had the largest number of double bonds per fatty acid (Table 2). Three out of 3 farms that had milks with the shortest chain length also had milks with the lowest number of double bonds, and 2 out of the 3 farms that had milks with the longest chain length had milks with the highest number of double bonds, indicating that there should be a positive correlation between fatty acid chain length and unsaturation.

There was a positive correlation $\left(P<0.001, \mathrm{R}^{2}=\right.$ 0.76 ) between increasing fatty acid chain length (carbon number) and increasing unsaturation (double bonds 
Table 1. Calculation of the mean fatty acid chain length and unsaturation for the fat in the modified milk used to calibrate the LactoScope Fourier transform infrared milk analyzer $^{1}$

\begin{tabular}{|c|c|c|c|c|c|c|c|c|c|c|c|}
\hline Item & $\begin{array}{l}\text { FAME}^{2} \\
\text { relative } \\
\text { area, \% }\end{array}$ & $\begin{array}{l}\text { Recovery } \\
\text { factor }^{3}\end{array}$ & $\begin{array}{l}\text { Recovery } \\
\text { corrected } \\
\text { FAME, }{ }^{4} \%\end{array}$ & $\begin{array}{c}\text { FAME } \\
\text { normalized to } \\
100 \%,{ }^{5} \text { wt/wt }\end{array}$ & $\begin{array}{l}\text { Portion of } \\
\text { the FAME } \\
\text { MW that } \\
\text { is } \text { FA }^{6}\end{array}$ & $\begin{array}{c}\text { Relative } \\
\text { fatty acid } \\
\text { composition, }{ }^{7} \%\end{array}$ & $\begin{array}{c}\text { Fatty acid } \\
\text { normalized to } \\
100 \%,{ }^{8} \text { wt/wt }\end{array}$ & $\begin{array}{c}\text { Fatty } \\
\text { acid MW }\end{array}$ & $\begin{array}{c}\text { Fatty acid } \\
\text { concentration, }{ }^{9} \\
\text { mmol }\end{array}$ & $\begin{array}{c}\text { Fatty acid } \\
\text { concentration } \\
\text { weighted for } \\
\text { carbon number }\end{array}$ & $\begin{array}{c}\text { Fatty acid } \\
\text { concentration } \\
\text { weighted for } \\
\text { number of } \\
\text { double bonds }{ }^{11}\end{array}$ \\
\hline \multicolumn{12}{|l|}{$\overline{\text { Fatty acid }}{ }^{12}$} \\
\hline C4:0 & 2.291 & 1.891 & 4.332 & 4.229 & 0.862 & 3.645 & 3.863 & 88.11 & 43.842 & 175.369 & 0.000 \\
\hline C6:0 & 1.431 & 1.533 & 2.194 & 2.142 & 0.892 & 1.911 & 2.025 & 116.16 & 17.431 & 104.588 & 0.000 \\
\hline $\mathrm{C} 8: 0$ & 0.894 & 1.307 & 1.169 & 1.141 & 0.912 & 1.041 & 1.103 & 144.21 & 7.647 & 61.173 & 0.000 \\
\hline C10:0 & 2.066 & 1.170 & 2.417 & 2.360 & 0.925 & 2.183 & 2.313 & 172.27 & 13.427 & 134.268 & 0.000 \\
\hline $\mathrm{C} 12: 0$ & 2.441 & 1.076 & 2.627 & 2.564 & 0.935 & 2.397 & 2.541 & 200.35 & 12.681 & 152.169 & 0.000 \\
\hline C14:0 & 8.822 & 1.023 & 9.023 & 8.808 & 0.942 & 8.297 & 8.793 & 228.38 & 38.501 & 539.011 & 0.000 \\
\hline C14:1 & 0.575 & 1.105 & 0.636 & 0.621 & 0.942 & 0.585 & 0.620 & 226.38 & 2.737 & 38.322 & 2.737 \\
\hline C15:0 & 0.914 & 0.906 & 0.828 & 0.808 & 0.945 & 0.764 & 0.809 & 242.41 & 3.339 & 50.081 & 0.000 \\
\hline C16:0 & 28.343 & 1.020 & 28.922 & 28.233 & 0.948 & 26.765 & 28.364 & 256.43 & 110.611 & $1,769.776$ & 0.000 \\
\hline C16:1 & 1.648 & 0.906 & 1.494 & 1.458 & 0.948 & 1.382 & 1.465 & 254.43 & 5.757 & 92.110 & 5.757 \\
\hline C17:0 & 0.680 & 0.778 & 0.529 & 0.517 & 0.951 & 0.491 & 0.521 & 270.48 & 1.925 & 32.718 & 0.000 \\
\hline C18:0 & 14.589 & 1.011 & 14.751 & 14.399 & 0.953 & 13.722 & 14.542 & 284.48 & 51.118 & 920.131 & 0.000 \\
\hline C18:1t4 & 0.022 & 1.174 & 0.026 & 0.026 & 0.953 & 0.024 & 0.026 & 282.48 & 0.092 & 1.653 & 0.092 \\
\hline $\mathrm{C} 18: 1+5$ & 0.000 & 1.174 & 0.000 & 0.000 & 0.953 & 0.000 & 0.000 & 282.48 & 0.000 & 0.000 & 0.000 \\
\hline C18:1t6-8 & 0.301 & 1.174 & 0.353 & 0.345 & 0.953 & 0.328 & 0.348 & 282.48 & 1.232 & 22.171 & 1.232 \\
\hline C18:1t9 & 0.260 & 1.174 & 0.305 & 0.298 & 0.953 & 0.284 & 0.300 & 282.48 & 1.064 & 19.147 & 1.064 \\
\hline $\mathrm{C} 18: 1 t 10$ & 0.616 & 1.174 & 0.723 & 0.706 & 0.953 & 0.673 & 0.713 & 282.48 & 2.524 & 45.429 & 2.524 \\
\hline C18:1t11 & 1.184 & 1.174 & 1.390 & 1.357 & 0.953 & 1.293 & 1.370 & 282.48 & 4.850 & 87.303 & 4.850 \\
\hline $\mathrm{C} 18: 1 t 12$ & 0.531 & 1.174 & 0.623 & 0.608 & 0.953 & 0.580 & 0.614 & 282.48 & 2.174 & 39.137 & 2.174 \\
\hline $\mathrm{C} 18: 1 c 9$ & 22.431 & 1.174 & 26.330 & 25.703 & 0.953 & 24.495 & 25.958 & 282.48 & 91.894 & 1.654 .095 & 91.894 \\
\hline $\mathrm{C} 18: 2 c 9, c 12$ & 2.441 & 1.144 & 2.792 & 2.725 & 0.952 & 2.595 & 2.750 & 280.48 & 9.803 & 176.462 & 19.607 \\
\hline $\mathrm{C} 20: 0$ & 0.169 & 0.640 & 0.108 & 0.106 & 0.957 & 0.101 & 0.107 & 312.54 & 0.343 & 6.853 & 0.000 \\
\hline $\mathrm{C} 18: 3$ & 0.382 & 0.959 & 0.367 & 0.358 & 0.952 & 0.341 & 0.361 & 278.48 & 1.297 & 23.349 & 3.891 \\
\hline CLA9-11 & 0.464 & 1.009 & 0.469 & 0.457 & 0.952 & 0.435 & 0.461 & 280.48 & 1.645 & 29.615 & 3.291 \\
\hline CLA $t 8, c 10$ & 0.034 & 1.009 & 0.034 & 0.033 & 0.95 & 0.031 & 0.033 & 280.48 & 0.119 & 2.142 & 0.238 \\
\hline Unknown & 6.469 & & 0.000 & 0.000 & & 0.000 & 0.000 & & & & \\
\hline Total & 100.000 & & 102.440 & 100.000 & & 94.363 & 100.000 & & 426.053 & $6,177.071$ & 139.351 \\
\hline Mean chain length ${ }^{13}$ & & & & & & & & & & 14.498 & \\
\hline Mean unsaturation ${ }^{14}$ & & & & & & & & & & & 0.327 \\
\hline
\end{tabular}

¿ ${ }^{1}$ Delta Instruments (Drachten, the Netherlands).

${ }^{2} \mathrm{FAME}=$ fatty acid methyl esters.

@ ${ }^{3}$ Recovery factor based on the ratio of the observed GLC output to the known output of the butter oil reference standard (CRM 164, Commission of the European Communities,

Community Bureau of Reference, Brussels, Belgium).

${ }^{4}$ Recovery corrected FAME $(\%)=$ FAME relative area $\% \times$ calculated recovery factor.

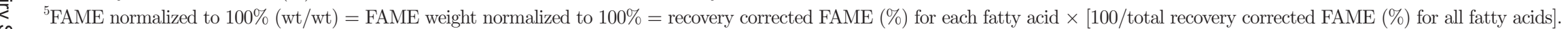

$\stackrel{\text { }}{\text {. }} \quad{ }^{6}$ Portion of the FAME molecular weight (MW) that is fatty acids used to convert the FAME to fatty acids (g/100 g of fat) = MW of FA/MW of FAME

${ }^{7}$ Relative fatty acid composition = relative fatty acid composition based on fatty acid weight, not FAME.

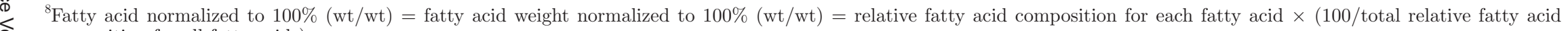
composition for all fatty acids).

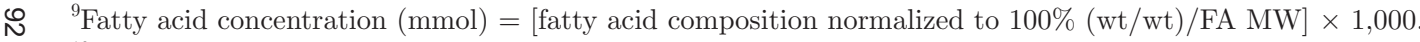

Z ${ }^{10}$ Fatty acid concentration weighted for carbon number $=$ fatty acid $(\mathrm{mmol}) \times$ number of carbons in the fatty acid chain

of ${ }^{11}$ Fatty acid concentration weighted for number of double bonds $=$ fatty acid $(\mathrm{mmol}) \times$ number of double bonds in the fatty acid chain

N ${ }^{12} t=$ trans; $c=$ cis.

${ }^{13}$ Mean chain length $=$ total fatty acid concentration weighted for carbon number (i.e., 6,177.071 mmol)/total fatty acid concentration (i.e., 426.053 mmol)

${ }^{14}$ Mean unsaturation = total fatty acid concentration weighted for number of double bonds (i.e., $139.351 \mathrm{mmol}$ )/total fatty acid concentration (i.e., $426.053 \mathrm{mmol}$ ). 
Table 2. Fatty acid composition, mean fatty acid chain length (CL, expressed as carbon number), and unsaturation (US, expressed as double bonds per fatty acid) of farm milks with the minimum, maximum, and mean CL and US for New York $(\mathrm{NY} ; \mathrm{n}=8)$, Texas $($ TX; $\mathrm{n}=27)$, and Vermont (VT; $\mathrm{n}=10)$

\begin{tabular}{|c|c|c|c|c|c|c|c|c|c|c|}
\hline \multirow[b]{2}{*}{ Item } & \multicolumn{3}{|c|}{ NY } & \multicolumn{4}{|c|}{ TX } & \multicolumn{3}{|c|}{ VT } \\
\hline & $\operatorname{Min}^{1}$ & $\operatorname{Max}^{2}$ & Mean & $\operatorname{Min}^{3}$ & $\operatorname{Max} \mathrm{CL}^{4}$ & $\operatorname{Max} \mathrm{US}^{5}$ & Mean & $\operatorname{Min}^{6}$ & $\operatorname{Max}^{7}$ & Mean \\
\hline \multicolumn{11}{|l|}{ Fatty acid, ${ }^{8} \%$} \\
\hline $\mathrm{C} 4: 0$ & 3.89 & 3.25 & 3.67 & 3.70 & 2.93 & 3.64 & 3.74 & 4.88 & 3.88 & 4.48 \\
\hline C6:0 & 2.65 & 1.54 & 2.13 & 2.41 & 1.54 & 1.71 & 2.04 & 2.61 & 2.07 & 2.44 \\
\hline $\mathrm{C} 8: 0$ & 1.71 & 0.82 & 1.25 & 1.48 & 0.87 & 0.87 & 1.13 & 1.38 & 1.11 & 1.34 \\
\hline C10:0 & 4.08 & 1.77 & 2.81 & 3.49 & 1.91 & 1.80 & 2.43 & 2.92 & 2.33 & 2.79 \\
\hline C12:0 & 4.69 & 1.99 & 3.17 & 4.05 & 2.14 & 2.01 & 2.67 & 3.11 & 2.49 & 3.01 \\
\hline C14:0 & 12.34 & 7.10 & 10.17 & 11.92 & 7.56 & 7.47 & 9.03 & 9.88 & 9.24 & 9.84 \\
\hline $\mathrm{C} 14: 1$ & 1.01 & 0.51 & 0.83 & 1.04 & 0.59 & 0.51 & 0.64 & 0.81 & 0.72 & 0.83 \\
\hline $\mathrm{C} 15: 0$ & 1.10 & 0.77 & 0.99 & 1.13 & 0.76 & 0.76 & 0.83 & 0.81 & 0.71 & 0.83 \\
\hline C16:0 & 32.08 & 25.02 & 27.92 & 29.46 & 26.96 & 24.68 & 26.53 & 29.32 & 24.95 & 27.07 \\
\hline C16:1 & 1.46 & 1.46 & 1.47 & 1.37 & 1.22 & 1.21 & 1.21 & 1.43 & 1.49 & 1.46 \\
\hline C17:0 & 0.43 & 0.51 & 0.54 & 0.57 & 0.41 & 0.49 & 0.49 & 0.55 & 0.47 & 0.52 \\
\hline C18:0 & 9.92 & 14.42 & 12.08 & 11.26 & 15.36 & 13.80 & 14.80 & 12.87 & 14.40 & 12.94 \\
\hline C18:1t4 & 0.00 & 0.05 & 0.02 & 0.02 & 0.02 & 0.06 & 0.04 & 0.00 & 0.03 & 0.01 \\
\hline C18:1t5 & 0.00 & 0.06 & 0.02 & 0.00 & 0.03 & 0.07 & 0.04 & 0.00 & 0.02 & 0.01 \\
\hline C18:1t6-8 & 0.24 & 0.82 & 0.43 & 0.25 & 0.51 & 0.80 & 0.49 & 0.32 & 0.41 & 0.31 \\
\hline C18:1t9 & 0.19 & 0.62 & 0.32 & 0.21 & 0.42 & 0.49 & 0.39 & 0.33 & 0.33 & 0.32 \\
\hline $\mathrm{C} 18: 1 t 10$ & 0.42 & 3.77 & 0.97 & 0.32 & 0.85 & 4.01 & 1.00 & 0.44 & 0.71 & 0.52 \\
\hline $\mathrm{C} 18: 1 t 11$ & 1.19 & 3.54 & 2.51 & 1.30 & 2.19 & 3.30 & 2.18 & 1.45 & 0.00 & 1.76 \\
\hline $\mathrm{C} 18: 1 t 12$ & 0.29 & 0.89 & 0.54 & 0.33 & 0.76 & 1.13 & 0.70 & 0.41 & 0.51 & 0.44 \\
\hline $\mathrm{C} 18: 1 c 9$ & 18.79 & 25.86 & 24.02 & 21.86 & 28.09 & 25.23 & 24.99 & 23.21 & 29.58 & 25.33 \\
\hline $\mathrm{C} 18: 2 c 9, c 12$ & 2.55 & 3.87 & 2.76 & 2.55 & 3.64 & 4.53 & 3.39 & 2.29 & 3.02 & 2.52 \\
\hline $\mathrm{C} 20: 0$ & 0.09 & 0.10 & 0.10 & 0.11 & 0.12 & 0.11 & 0.13 & 0.10 & 0.12 & 0.10 \\
\hline C18:3 & 0.42 & 0.35 & 0.44 & 0.64 & 0.20 & 0.33 & 0.39 & 0.39 & 0.43 & 0.44 \\
\hline CLA9-11 & 0.44 & 0.91 & 0.79 & 0.51 & 0.87 & 0.94 & 0.67 & 0.49 & 0.93 & 0.68 \\
\hline $\mathrm{CLA} t 8, c 10$ & 0.04 & 0.02 & 0.04 & 0.03 & 0.05 & 0.06 & 0.05 & 0.00 & 0.04 & 0.01 \\
\hline Mean CL & 13.830 & 15.035 & 14.389 & 14.092 & 15.063 & - & 14.539 & 13.904 & 14.520 & 14.111 \\
\hline Mean US & 0.250 & 0.416 & 0.331 & 0.286 & - & 0.417 & 0.345 & 0.285 & 0.362 & 0.318 \\
\hline
\end{tabular}

${ }^{1}$ Farm was NY-1.

${ }^{2}$ Farm was NY-2.

${ }^{3}$ Farm was TX-12.

${ }^{4}$ Farm was TX-3.

${ }^{5}$ Farm was TX-17.

${ }^{6}$ Farm was VT-9.

${ }^{7}$ Farm was VT-1.

${ }^{8} t=$ trans; $c=$ cis.

per fatty acid) in the farm milks (Figure 1). Generally, stage of lactation (Lynch et al., 1992) and dairy cattle feeding practices that incorporate more fat in the dairy ration result in longer average chain lengths and more unsaturation of fatty acids in milk. Variations in the mean molecular weight (i.e., fatty acid chain length) and unsaturation that occur because of stage of lactation have been reported to affect the accuracy of MIR milk analysis (Sjaunja, 1984). Protected lipid feeding techniques designed either to change milk fatty acid composition or to significantly increase the energy intake by dairy cows can cause changes in milk composition that are large enough to influence the accuracy of MIR milk testing. This has been demonstrated in several previous studies in which cows fed protected sunflower-soybean supplements (Dunkley et al., 1977), protected tallow (Franke et al., 1977), and whole cot- tonseed (Franke et al., 1981) produced milk that had an increased average chain length of milk fatty acids and that resulted in lower fat tests with MIR analysis than with Babcock analysis.

The mean fatty acid chain length and unsaturation observed for the 45 farm milks in the present study was 14.417 carbons and 0.337 double bonds per fatty acid, respectively (Table 3 ). The range of fatty acid chain lengths across the 45 farms was 1.23 carbons, and the range in unsaturation was 0.167 double bonds per fatty acid. As measured with chemical testing methods, the fat content of the farm milks ranged from 2.8682 to $5.7254 \%$, lactose ranged from 4.4498 to $4.8929 \%$, and true protein ranged from 2.7666 to $3.7821 \%$ (Table 3), indicating that a good sampling of the milk population was obtained. There was no correlation $(P>0.05)$ between chemical tests for fat or lactose content and fatty 


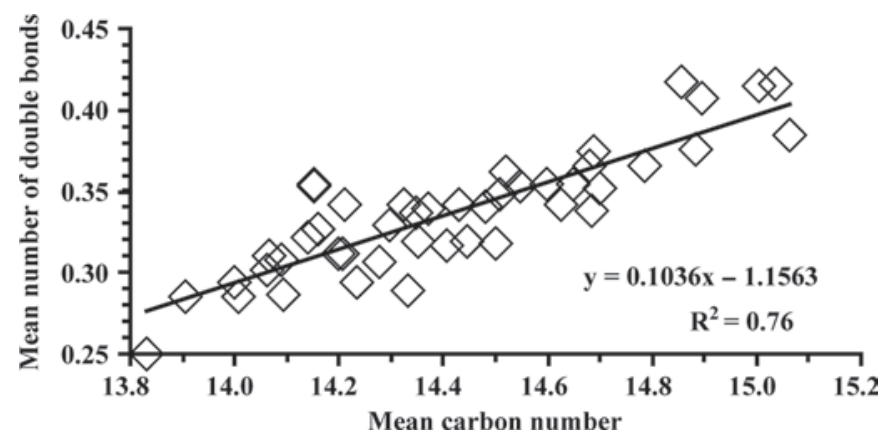

Figure 1. Change in unsaturation (double bonds per fatty acid) as a function of fatty acid chain length (carbons) for 45 farm milks from New York $(\mathrm{n}=8)$, Texas $(\mathrm{n}=27)$, and Vermont $(\mathrm{n}=10)$.

acid chain length (data not shown). True protein content measured by Kjeldahl decreased $(P<0.05)$ with increasing fatty acid chain length (i.e., slope $=-0.308 \%$ true protein per unit increase in chain length), but the coefficient of determination (0.17) was low. There was a decrease $(P<0.05)$ in fat by chemical analysis (i.e., slope $=-6.868 \%$ fat) and in true protein content by Kjeldahl with increasing unsaturation of fatty acids (i.e., slope $=-3.614 \%$ true protein per unit increase in unsaturation), but the coefficients of determination were low, 0.16 and 0.33 , respectively. No change $(P>$ $0.05)$ in lactose content by chemical analysis was detected with increasing unsaturation. The FFA content of milk from the 45 farm milks ranged from 0.111 to $0.513 \mathrm{mEq} / \mathrm{kg}$ of milk and had a mean of $0.226 \mathrm{mEq} /$ $\mathrm{kg}$ of milk (Table 3). These values are similar to those reported for producer calibration milks, for which the range was 0.098 to 0.463 and the mean was $0.229 \mathrm{mEq} /$ $\mathrm{kg}$ of milk (Kaylegian et al., 2007).

\section{MIR Analysis of Farm Milk}

The MIR-predicted values for fat B, lactose, true protein, and fat A for all 45 farm milks, and for each of their FFA contents, are presented in Table 3. A high FFA content in milk, which is associated with lipolysis, has been reported to decrease the MIR fat A prediction of fat content and increase the MIR prediction of protein content (Robertson et al., 1981; van de Voort et al., 1987). No correlation $(P>0.05)$ was detected between the FFA content and the MIR prediction of fat $\mathrm{B}$, fat $\mathrm{A}$, or protein content for the 45 farm milks used in this study.

The difference between MIR fat B prediction and reference chemistry was positively correlated $(P<$ 0.001) with chain length (Figure 2a), and the difference between fat $\mathrm{A}$ prediction and reference chemistry was negatively correlated $(P<0.001)$ with chain length (Figure 2b). These observations are consistent with those reported by Kaylegian et al. (2009), in which the fat $B$ readings increased and the fat $A$ readings decreased relative to reference chemistry as fatty acid chain length increased.

The difference between the MIR fat B and fat A predicted fat content of the farm milks had a positive $(P<$ $\left.0.001, \mathrm{R}^{2}=0.81\right)$ correlation with the increase in fatty acid chain length (Figure 3 ). These data support the approach used in this study to select farm milks with a wide range of differences between MIR fat B and fat A values as a technique to select milk with different fatty acid compositions. In general, the larger the difference between the fat B and fat A MIR-predicted values (either positive or negative), the farther the fatty acid chain length of that milk will be from the mean fatty acid chain length of the milks used to calibrate the MIR milk analyzer.

When the fat B minus reference chemistry, the fat A minus reference chemistry, or the difference between fat $\mathrm{B}$ and fat $\mathrm{A}$ is zero, then the fatty acid chain length of that milk is approximately the same as the mean of the milk used to calibrate the MIR milk analyzer. In Figure 3, the point where the regression line had a zero value for fat $\mathrm{B}$ minus fat $\mathrm{A}$ is 14.4 carbons, and this is a prediction of the mean fatty acid chain length of the milk used to make the modified milk calibration set. The fatty acid chain length of the modified milks used to calibrate the MIR milk analyzer was determined directly by GLC and was similar, with a mean of 14.5 carbons (Table 1).

\section{Improving the MIR Prediction of Milk Fat Content by Adjustment of Fat B MIR-Predicted Values for a Change in Unsaturation}

Using model emulsions of skim milk and pure monoacid triglycerides, Kaylegian et al. (2009) determined that fat B readings decreased by $-0.4021 \%$ per unit increase in unsaturation (double bonds per fatty acid) per $1 \%$ fat. The fat $B$ readings from the 45 farm milks (Table 3) were corrected for the effect of variation in unsaturation by using the following equation: $[\mathrm{y}=$ (fat B) $+\{0.4021 \times[($ unsaturation of milk tested $)-($ mean unsaturation of the calibration set)]\} $\times$ (fat B)]. The value used for mean unsaturation of the modified milk calibration set was determined by running a regression analysis on fat A minus ether (y) as a function of number of double bonds (x) for the 45 farm milks. The calculated value (using the regression equations) for double bonds per fatty acid for which the difference between fat $\mathrm{A}$ and reference chemistry was zero corresponded to 0.337 double bonds per fatty acid. This value was close to the average unsaturation (0.327) of the calibration milks used in this study that was mea- 
Table 3. Mean fatty acid chain length (CL, expressed as carbon number) and unsaturation (US, expressed as double bonds per fatty acid), reference chemistry, MIR ${ }^{1}$-predicted milk component values, and FFA content for 45 farm milks from New York (NY), Texas (TX), and Vermont $(\mathrm{VT})$

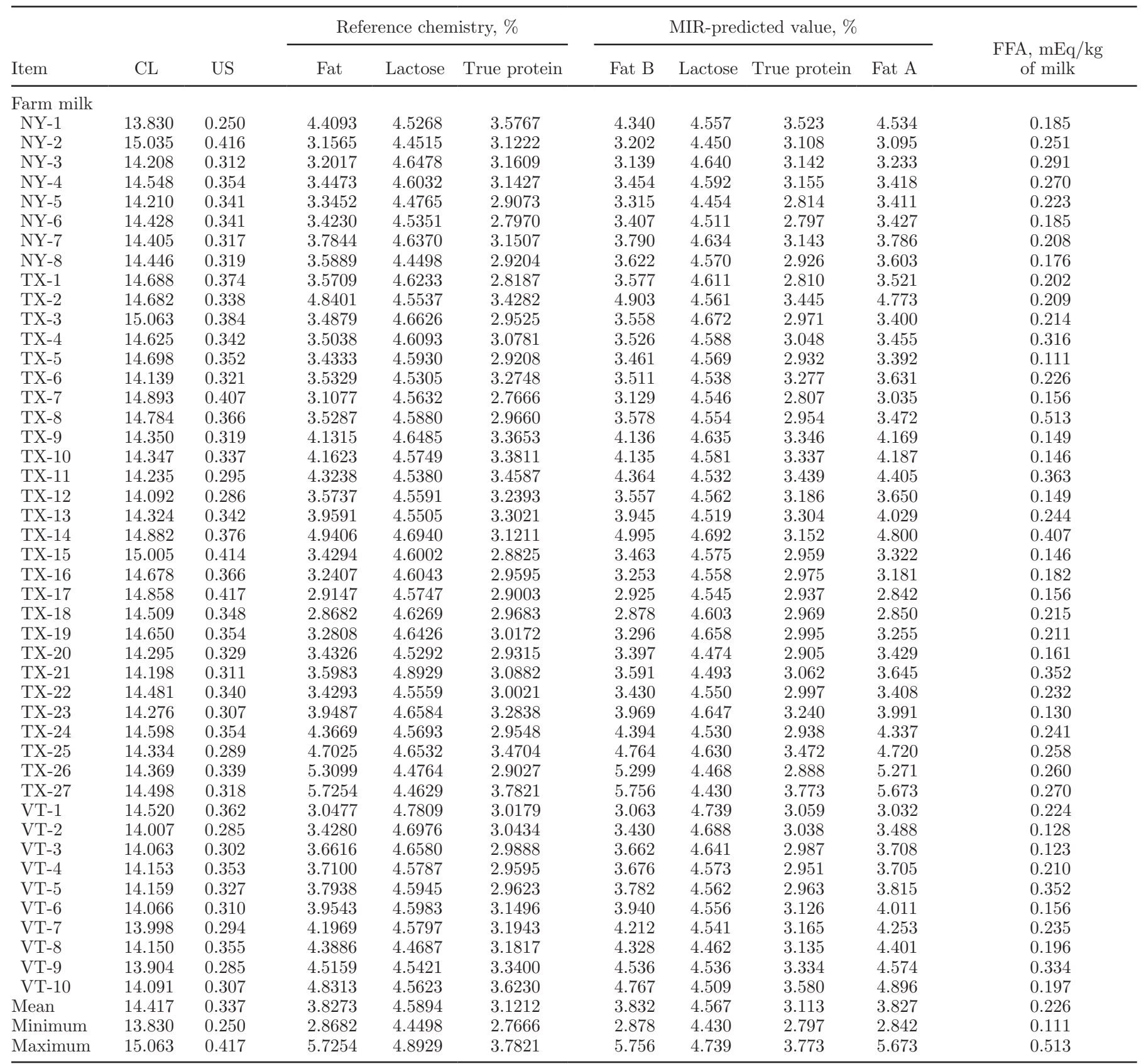

${ }^{1}$ Mid-infrared.

sured independently by GLC and that is reported in Table 1.

The correlation of fat $\mathrm{B}$ minus reference chemistry with mean fatty acid chain length was improved from a coefficient of determination of 0.42 (Figure 2a) to 0.89 (Figure 4) by correcting fat $\mathrm{B}$ for the variation in total unsaturation. This major improvement in the correlation of fat $\mathrm{B}$ data with a change in fatty acid chain length demonstrated that the correction greatly reduced the effect of unsaturation on the fat B results. The factor (i.e., $-0.4021 \%$ ) used for correction, based on the study of model milk systems (Kaylegian et al., 2009), was varied to higher and lower values in the correction of fat $\mathrm{B}$ for unsaturation, but it did not improve the coefficient of determination of the relationship between fat $\mathrm{B}$ corrected for unsaturation minus reference 
(a)

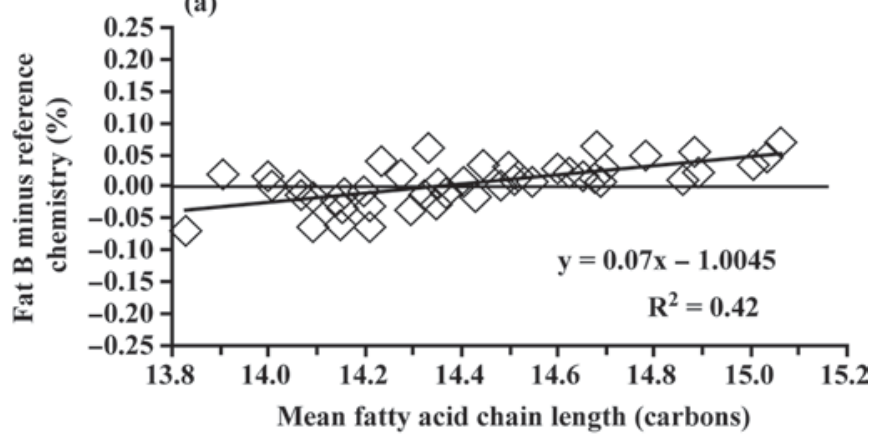

(b)

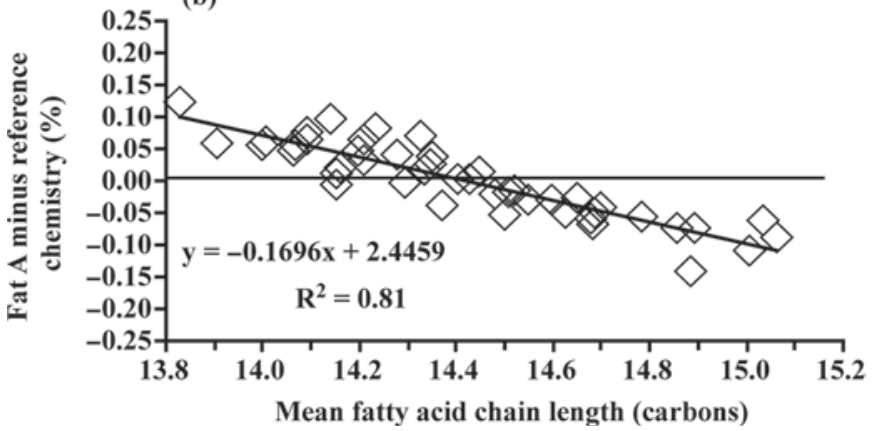

Figure 2. Mid-infrared fat prediction minus fat reference chemistry as a function of fatty acid chain length for 45 farm milks from New York $(n=8)$, Texas $(n=27)$, and Vermont $(n=10)$ : (a) fat B; (b) fat A.

chemistry and fatty acid chain length (data not shown). This indicated that the correction value for removal of the effect of variation in fatty acid unsaturation at the fat $\mathrm{B}$ wavelength determined with model milk emulsions that varied only in unsaturation (Kaylegian et al., 2009) worked well with the farm milks that varied in chain length and unsaturation simultaneously.

The variation in MIR fat B predictions of milk fat content ranged from $-0.07 \%$ lower to $0.07 \%$ higher, and fat A ranged from $-0.14 \%$ lower to $0.12 \%$ higher than reference chemistry (Table 4). Although the over-

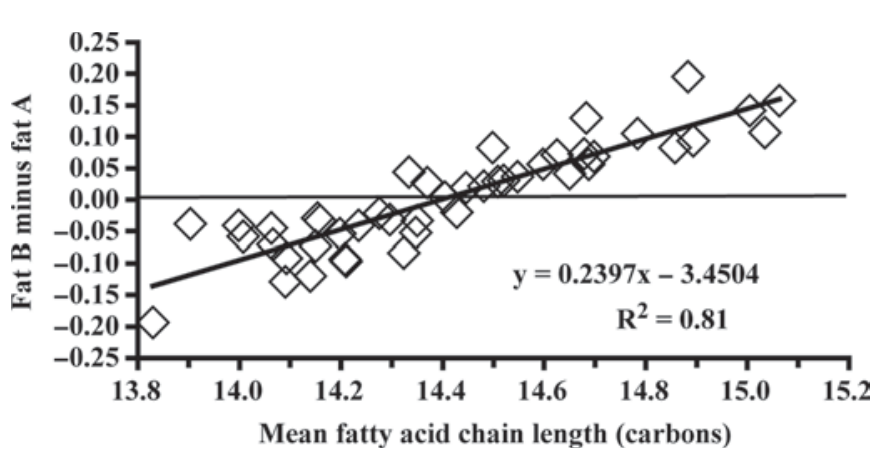

Figure 3. Mid-infrared predicted fat $\mathrm{B}$ minus fat $\mathrm{A}$ values as a function of fatty acid chain length for 45 farm milks from New York (n $=8)$, Texas $(\mathrm{n}=27)$, and Vermont $(\mathrm{n}=10)$. all mean predicted fat for 45 farms was in very good agreement with reference chemistry (Table 4), the deviations from chemistry on individual farms could lead to systematic overpayment of some and underpayment of others. Within a set of producer milk calibration samples for an infrared analyzer, uncontrolled milk-tomilk variation in fatty acid composition causes errors in setting the secondary slope. Variations in the secondary slope and intercept from one producer milk calibration set to the next because of variation in fatty acid composition within a calibration set causes increased uncertainty of calibration, as reported by Kaylegian et al., (2006). The calculated correction to remove the effect of unsaturation from the fat $B$ readings for each of the 45 milks caused the fat $\mathrm{B}$ prediction of fat content to increase when unsaturation was higher than the average unsaturation of the calibration milks and to decrease when unsaturation was lower than the average unsaturation of the calibration milks. The mean differences (MD) of the residuals of MIR fat prediction and reference chemistry for all 3 estimates of fat (i.e., fat $\mathrm{B}$, fat $\mathrm{B}$ corrected for unsaturation, and fat $\mathrm{A}$ ) for the 45 milks were very close to the reference chemistry, but the SDD of differences were quite different (Table 4). The fat B SDD was lower than the fat A SDD, which is in agreement with a previous report (Biggs and McKenna, 1989). The SDD of the fat B corrected for the variation in unsaturation among milks and reference chemistry was even larger than the SDD for fat A (Table 4). Thus, fat B corrected for unsaturation by itself was not as good a predictor of milk fat as fat B or fat A alone.

Biggs and McKenna (1989) reported that a 73:27 combination of fat B and fat A values gave a lower SDD than the fat B alone. Ratios ranging from 70:30 to 40:60 of the fat $\mathrm{B}$ corrected for unsaturation combined with the fat A were evaluated to determine their impact on MD and SDD for MIR prediction of fat. All ratios gave

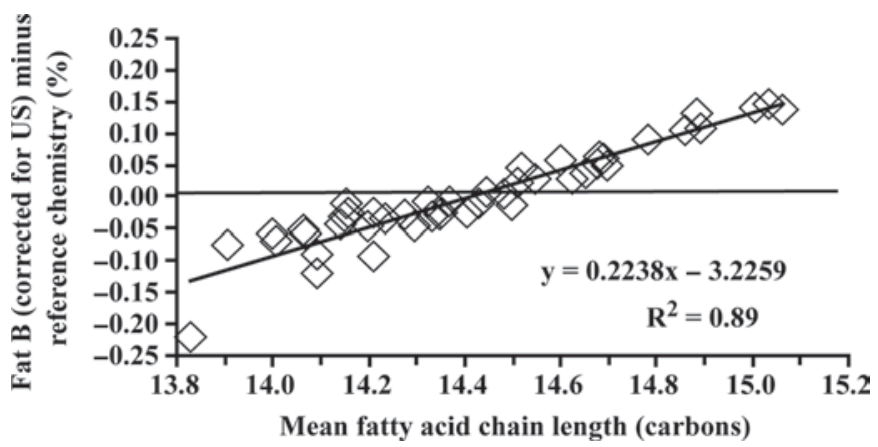

Figure 4. Mid-infrared predicted fat B corrected for the effect of unsaturation (US) minus fat reference chemistry as a function of fatty acid chain length for 45 farm milks from New York $(\mathrm{n}=8)$, Texas (n $=27)$, and Vermont $(\mathrm{n}=10)$. 
Table 4. Fat B, fat B corrected for unsaturation (US), fat A, reference chemistry (ether), and their residual differences from reference fat values (mid-infrared minus ether) for 45 farm milks from New York $(\mathrm{NY}, \mathrm{n}=8)$, Texas $(\mathrm{TX}, \mathrm{n}=27)$, and Vermont $(\mathrm{VT}, \mathrm{n}=10)$

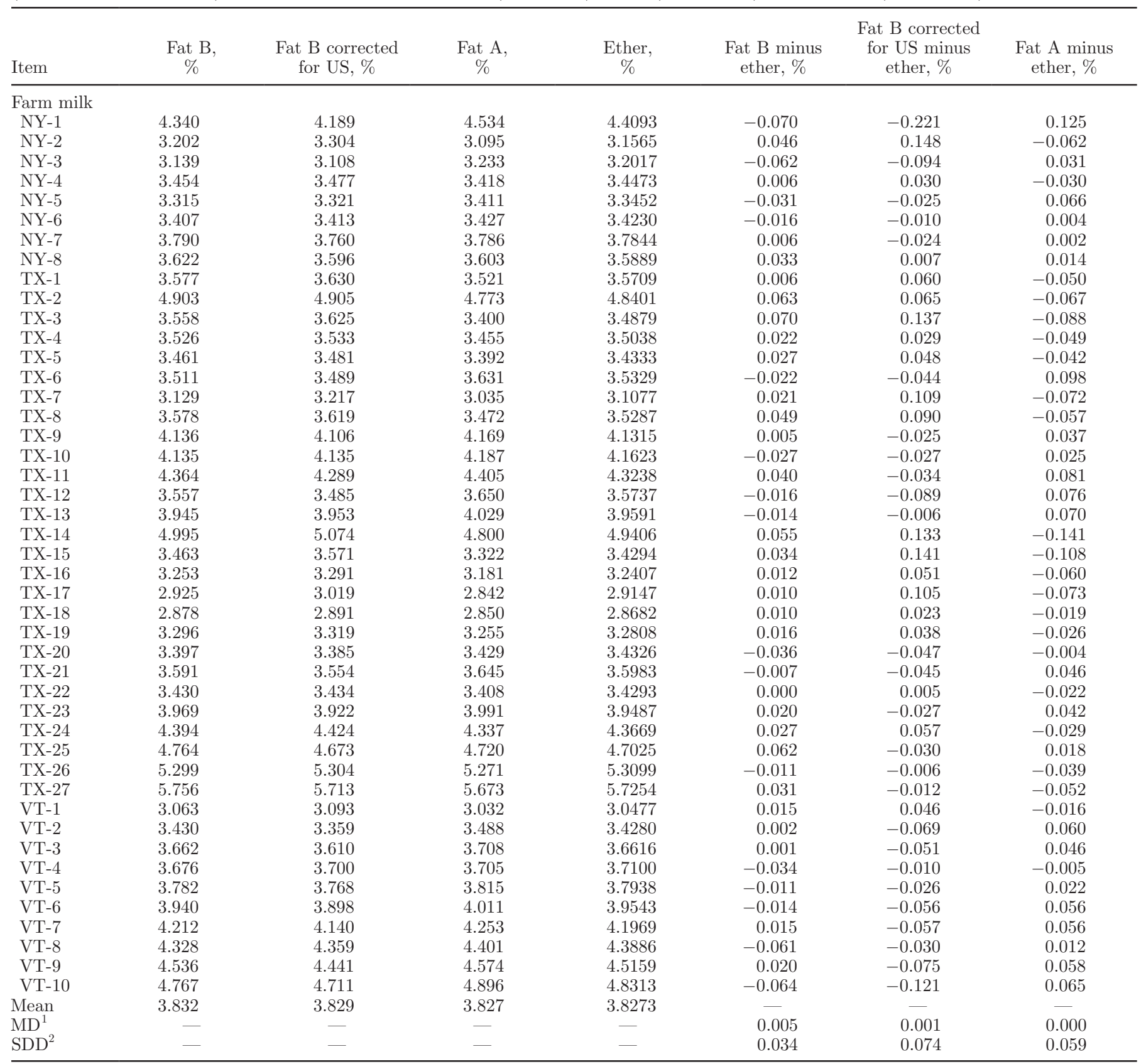

${ }^{1} \mathrm{MD}=$ mean difference.

${ }^{2} \mathrm{SDD}=\mathrm{SD}$ of the difference.

very good average agreement with reference chemistry (i.e., small MD), but the SDD of the residual differences between reference chemistry and MIR-predicted fat changed dramatically with ratio (Table 5 ). The ratio that gave the smallest SDD (0.0160) between MIR fat prediction and reference chemistry was $45 \%$ fat B corrected for unsaturation and $55 \%$ fat $\mathrm{A}$. The fat $\mathrm{B}$ (with no correction for unsaturation) and fat A data from the
45 milks were combined in a 73:27 ratio as suggested by Biggs and McKenna (1989) and produced a larger SDD of 0.0201 . The performance of other fat B (with no correction for unsaturation) and fat A ratios was evaluated and the ratio of 69:31 gave the lowest SDD (0.0196) for this group of 45 milks. The 69:31 fat B-to-fat A ratio $(\mathrm{SDD}=0.0196$; Table 5$)$ was better than either fat $\mathrm{B}$ $(\mathrm{SDD}=0.034$; Table 4$)$ or fat $\mathrm{A}(\mathrm{SDD}=0.059$; Table 
Table 5. Residual differences (mid-infrared minus reference fat chemistry) for various ratios of fat B corrected for unsaturation (US) and fat $\mathrm{A}$, and for various ratios of fat B not corrected for unsaturation and fat A for 45 farm milks from New York $(\mathrm{NY}, \mathrm{n}=8)$, Texas $(\mathrm{TX}, \mathrm{n}=27)$, and Vermont (VT, $\mathrm{n}=10$ )

Mid-infrared minus reference fat chemistry

\begin{tabular}{|c|c|c|c|c|c|c|c|c|}
\hline \multirow[b]{2}{*}{ Item } & \multicolumn{5}{|c|}{ Ratio of fat B corrected for US to fat A, $\%$} & \multicolumn{3}{|c|}{ Ratio of fat B to fat A, \% } \\
\hline & $70: 30$ & $60: 40$ & $50: 50$ & $45: 55$ & $40: 60$ & $73: 27$ & $70: 30$ & $69: 31$ \\
\hline \multicolumn{9}{|c|}{ Farm milk } \\
\hline NY-1 & -0.1171 & -0.0825 & -0.0480 & -0.0308 & -0.0135 & -0.0172 & -0.0113 & -0.0094 \\
\hline NY-2 & 0.0849 & 0.0639 & 0.0430 & 0.0326 & 0.0221 & 0.0167 & 0.0134 & 0.0124 \\
\hline NY-3 & -0.0565 & -0.0440 & -0.0315 & -0.0252 & -0.0190 & -0.0371 & -0.0343 & -0.0334 \\
\hline NY-4 & 0.0118 & 0.0059 & 0.0000 & -0.0030 & -0.0060 & -0.0033 & -0.0044 & -0.0048 \\
\hline NY-5 & 0.0025 & 0.0116 & 0.0206 & 0.0251 & 0.0297 & -0.0046 & -0.0017 & -0.0007 \\
\hline NY-6 & -0.0055 & -0.0041 & -0.0027 & -0.0020 & -0.0013 & -0.0104 & -0.0098 & -0.0096 \\
\hline NY-7 & -0.0164 & -0.0137 & -0.0111 & -0.0098 & -0.0085 & 0.0050 & 0.0048 & 0.0048 \\
\hline NY-8 & 0.0095 & 0.0102 & 0.0109 & 0.0112 & 0.0115 & 0.0280 & 0.0274 & 0.0272 \\
\hline TX-1 & 0.0267 & 0.0157 & 0.0048 & -0.0007 & -0.0062 & -0.0090 & -0.0107 & -0.0113 \\
\hline TX-2 & 0.0251 & 0.0119 & -0.0013 & -0.0079 & -0.0144 & 0.0279 & 0.0240 & 0.0227 \\
\hline TX-3 & 0.0699 & 0.0474 & 0.0249 & 0.0136 & 0.0024 & 0.0273 & 0.0226 & 0.0210 \\
\hline TX-4 & 0.0059 & -0.0019 & -0.0097 & -0.0136 & -0.0174 & 0.0032 & 0.0011 & 0.0004 \\
\hline TX-5 & 0.0210 & 0.0120 & 0.0030 & -0.0014 & -0.0059 & 0.0086 & 0.0065 & 0.0058 \\
\hline TX-6 & -0.0015 & 0.0127 & 0.0269 & 0.0340 & 0.0411 & 0.0102 & 0.0138 & 0.0150 \\
\hline TX-7 & 0.0548 & 0.0366 & 0.0185 & 0.0094 & 0.0003 & -0.0040 & -0.0068 & -0.0078 \\
\hline TX-8 & 0.0460 & 0.0314 & 0.0167 & 0.0094 & 0.0021 & 0.0204 & 0.0172 & 0.0161 \\
\hline TX-9 & -0.0066 & -0.0003 & 0.0060 & 0.0091 & 0.0123 & 0.0135 & 0.0145 & 0.0148 \\
\hline TX-10 & -0.0117 & -0.0064 & -0.0012 & 0.0014 & 0.0041 & -0.0130 & -0.0114 & -0.0109 \\
\hline TX-11 & 0.0002 & 0.0118 & 0.0233 & 0.0291 & 0.0348 & 0.0511 & 0.0524 & 0.0528 \\
\hline TX-12 & -0.0395 & -0.0230 & -0.0066 & 0.0017 & 0.0099 & 0.0086 & 0.0114 & 0.0123 \\
\hline TX-13 & 0.0164 & 0.0240 & 0.0316 & 0.0354 & 0.0392 & 0.0088 & 0.0113 & 0.0122 \\
\hline TX-14 & 0.0510 & 0.0236 & -0.0037 & -0.0174 & -0.0311 & 0.0019 & -0.0039 & -0.0059 \\
\hline TX-15 & 0.0666 & 0.0417 & 0.0168 & 0.0043 & -0.0081 & -0.0045 & -0.0087 & -0.0102 \\
\hline TX-16 & 0.0174 & 0.0064 & -0.0047 & -0.0102 & -0.0158 & -0.0071 & -0.0093 & -0.0100 \\
\hline TX-17 & 0.0514 & 0.0336 & 0.0159 & 0.0070 & -0.0018 & -0.0123 & -0.0148 & -0.0156 \\
\hline TX-18 & 0.0103 & 0.0061 & 0.0020 & 0.0000 & -0.0021 & 0.0024 & 0.0015 & 0.0012 \\
\hline TX-19 & 0.0187 & 0.0123 & 0.0059 & 0.0027 & -0.0005 & 0.0044 & 0.0031 & 0.0027 \\
\hline TX-20 & -0.0342 & -0.0299 & -0.0255 & -0.0234 & -0.0212 & -0.0272 & -0.0262 & -0.0259 \\
\hline TX-21 & -0.0174 & -0.0083 & 0.0008 & 0.0053 & 0.0099 & 0.0072 & 0.0088 & 0.0093 \\
\hline TX-22 & -0.0029 & -0.0056 & -0.0082 & -0.0096 & -0.0109 & -0.0056 & -0.0063 & -0.0065 \\
\hline TX-23 & -0.0064 & 0.0005 & 0.0073 & 0.0108 & 0.0142 & 0.0262 & 0.0268 & 0.0271 \\
\hline TX-24 & 0.0311 & 0.0225 & 0.0138 & 0.0095 & 0.0051 & 0.0118 & 0.0101 & 0.0095 \\
\hline TX-25 & -0.0154 & -0.0106 & -0.0059 & -0.0035 & -0.0011 & 0.0501 & 0.0488 & 0.0483 \\
\hline TX-26 & -0.0159 & -0.0191 & -0.0224 & -0.0240 & -0.0256 & -0.0185 & -0.0194 & -0.0196 \\
\hline TX-27 & -0.0242 & -0.0281 & -0.0321 & -0.0341 & -0.0361 & 0.0086 & 0.0061 & 0.0053 \\
\hline VT-1 & 0.0273 & 0.0211 & 0.0150 & 0.0119 & 0.0088 & 0.0069 & 0.0059 & 0.0056 \\
\hline VT-2 & -0.0302 & -0.0173 & -0.0043 & 0.0022 & 0.0087 & 0.0179 & 0.0197 & 0.0203 \\
\hline VT-3 & -0.0221 & -0.0124 & -0.0027 & 0.0022 & 0.0070 & 0.0130 & 0.0144 & 0.0148 \\
\hline $\mathrm{VT}-4$ & -0.0087 & -0.0082 & -0.0077 & -0.0075 & -0.0073 & -0.0266 & -0.0257 & -0.0254 \\
\hline VT-5 & -0.0119 & -0.0071 & -0.0023 & 0.0001 & 0.0025 & -0.0025 & -0.0015 & -0.0011 \\
\hline VT-6 & -0.0225 & -0.0112 & 0.0000 & 0.0056 & 0.0112 & 0.0048 & 0.0069 & 0.0076 \\
\hline VT-7 & -0.0232 & -0.0119 & -0.0007 & 0.0050 & 0.0106 & 0.0263 & 0.0275 & 0.0279 \\
\hline VT-8 & -0.0174 & -0.0131 & -0.0089 & -0.0068 & -0.0047 & -0.0413 & -0.0391 & -0.0383 \\
\hline VT-9 & -0.0352 & -0.0219 & -0.0086 & -0.0020 & 0.0047 & 0.0301 & 0.0312 & 0.0316 \\
\hline VT-10 & -0.0651 & -0.0465 & -0.0279 & -0.0186 & -0.0093 & -0.0292 & -0.0253 & -0.0240 \\
\hline $\mathrm{MD}^{1}$ & 0.0009 & 0.0008 & 0.0007 & 0.0006 & 0.0005 & 0.0037 & 0.0036 & 0.0035 \\
\hline $\mathrm{SDD}^{2}$ & 0.0374 & 0.0263 & 0.0178 & 0.0160 & 0.0167 & 0.0201 & 0.0196 & 0.0195 \\
\hline
\end{tabular}

${ }^{1} \mathrm{MD}=$ mean difference.

${ }^{2} \mathrm{SDD}=\mathrm{SD}$ of the difference.

4) alone, but was not as good as the 45:55 combination of the fat B corrected for unsaturation with fat A (SDD $=0.0160 ;$ Table 5 ).

The improved accuracy of MIR fat predictions obtained by using a ratio of 45:55 fat $\mathrm{B}$ corrected for unsaturation (based on GLC measurement of unsatura- tion) and fat A demonstrated the technical feasibility of improving the accuracy of MIR fat predictions with the fixed-filter approach to calibration. The approach used to correct the fat B data for unsaturation by using an estimate of unsaturation from GLC analysis of each milk is not practical for routine milk analysis. However, 
it does demonstrate that if a rapid estimate of unsaturation for each milk could be obtained easily, then the accuracy of MIR prediction of fat using the fixed-filter approach could be improved.

The range of wavelengths used in FT MIR milk analyzers is from 3.3 to $10 \mu \mathrm{m}\left(3,000\right.$ to $\left.1,000 \mathrm{~cm}^{-1}\right)$. It is possible that data from areas of the MIR spectrum other than the fixed-filter wavelengths could be used with multivariate statistics to achieve better accuracy of MIR fat predictions in milk. To explore the feasibility of this option, fat was extracted from milks that differed greatly in unsaturation, and MIR spectra were collected from 3.3 to $10 \mu \mathrm{m}$ using an FT MIR spectrometer (Nicolet Instrument Corp., Madison, WI) with a ZnSe attenuated total reflectance crystal accessory (Thermo Spectra-Tech, Madison, WI) with a resolution of $4 \mathrm{~cm}^{-1}$ and 256 scans per sample using OMNIC software (OMNIC E.S.P., Nicolet Instrument Corp.). The MIR spectra of the pure milk fats differed slightly from each other at the fat $\mathrm{B}(\mathrm{C}-\mathrm{H}$ stretch $)$ and fat $\mathrm{A}(\mathrm{C}=\mathrm{O}$ stretch $)$ wavelengths $[3.51$ and $5.72 \mu \mathrm{m}$ $\left(2,851\right.$ and $\left.1,748 \mathrm{~cm}^{-1}\right)$, respectively]. Kaylegian et al. (2009) evaluated milk spectra from 3 to $10 \mu \mathrm{m}$ for a series of milk emulsions that differed only in unsaturation and reported that sequential differences in the MIR absorbance of these samples were not present at wavelengths other than fat $\mathrm{B}$ and fat $\mathrm{A}$ wavelengths. This may indicate that multivariate approaches such as classical least squares regression, inverse least squares regression, partial least squares regression, and principal component regression could have a difficult time correctly compensating for variation in fatty acid chain length and unsaturation beyond what has been done with the traditional fixed-filter approach using intercorrection factors. In fact, Luinge et al. (1993) evaluated 55 raw producer milks for calibration and validation performance, and concluded that there were no significant differences between reference chemistry minus FT MIR fat predictions using multivariate approaches and reference chemistry minus MIR fat predictions using a fixed-filter approach. Similar conclusions were made by van de Voort et al. (1992). Thus, although multivariate calibration approaches would seem to have the potential to provide improved accuracy of fat testing by MIR, the reality is that no one has been able to demonstrate a significant performance improvement with multivariate approaches in comparison with a properly run fixed-filter approach.

\section{CONCLUSIONS}

The mean fatty acid chain length was 14.417 carbons and the mean unsaturation was 0.337 double bonds per fatty acid for 45 farm milks collected from New York,
Texas, and Vermont. The range of fatty acid chain lengths was 1.23 carbons and the range in unsaturation was 0.167 double bonds per fatty acid among 45 farms. Fat B MIR fat predictions increased and fat A MIR predictions decreased relative to reference chemistry with increasing fatty acid chain length. When the fat B MIR fat predictions were corrected for sample-to-sample variation in unsaturation (measured by GLC analysis of each milk), the positive correlation between fat B and fatty acid chain lengths increased from a coefficient of determination of 0.42 to 0.89 . A $45: 55$ ratio of fat $\mathrm{B}$ corrected for unsaturation and fat A gave a smaller SDD between MIR prediction and reference chemistry fat values (0.0160) than any ratio of the fat B (without correction for unsaturation) and fat $\mathrm{A}$ or either fat B or fat A alone. The present study demonstrated the technical feasibility of this approach. If a rapid procedure could be developed to determine the unsaturation of fat in milk and could be used in real-time testing to correct the MIR fat B readings, improved accuracy of MIR milk fat predictions could be achieved.

\section{ACKNOWLEDGMENTS}

The authors thank Cornell University staff members Maureen Chapman, Jessica Mallozzi, and Karen Wojciechowski for their technical assistance, and Lloyd Metzger (South Dakota State University, Brookings) for FT MIR spectra of milk fats of different unsaturation. The authors thank the Test Procedures Committee of the USDA, Dairy Programs, Federal Milk Markets, for their financial support of this research.

\section{REFERENCES}

AOAC. 2000. Official Methods for Analysis. AOAC Int., Gaithersburg, MD.

Biggs, D. A., and D. McKenna. 1989. Alternative methods for infrared analysis of fat in milk: Interlaboratory study. J. AOAC 72:724734 .

Dunkley, W. L., A. A. Franke, and L. M. Smith. 1977. Determining fat, protein, and lactose in milk from cows fed formaldehyde protected sunflower-soybean supplement. J. Dairy Sci. 60:45-52.

Franke, A. A., W. L. Dunkley, and N. E. Smith. 1977. Influence of feeding protected tallow on accuracy of analysis by infrared milk analyzer. J. Dairy Sci. 60:1870-1874.

Franke, A. A., W. L. Dunkley, and N. E. Smith. 1981. Influence of dairy rations with whole cottonseed or extruded soybeans on accuracy of analysis for milk components. J. Dairy Sci. 64:2185-2191.

Kaylegian, K. E., G. E. Houghton, J. M. Lynch, J. R. Fleming, and D. M. Barbano. 2006. Calibration of infrared milk analyzers: Modified milk versus producer milk. J. Dairy Sci. 89:2817-2832.

Kaylegian, K. E., J. M. Lynch, J. R. Fleming, and D. M. Barbano. 2009. Influence of fatty acid chain length and unsaturation on midinfrared milk analysis. J. Dairy Sci. 92:2485-2501.

Kaylegian, K. E., J. M. Lynch, J. R. Fleming, and D. M. Barbano. 2007. Lipolysis and proteolysis of modified and producer milk used for calibration of mid-infrared milk analyzers. J. Dairy Sci. 90:602-615.

Luinge, H. J., E. Hop, E. T. G. Lutz, J. A. van Hemert, and E. A. M. de Jong. 1993. Determination of the fat, protein and lactose 
content of milk using Fourier transform infrared spectrometry. Anal. Chim. Acta 284:419-433.

Lynch, J. M., D. M. Barbano, D. E. Bauman, G. F. Hartnell, and M. A. Nemeth. 1992. Effect of a prolonged release formulation of $\mathrm{N}$-methionyl bovine somatotropin (sometribove) on production and composition of milk fat. J. Dairy Sci. 75:1794-1809.

Lynch, J. M., D. M. Barbano, M. Schweisthal, and J. R. Fleming. 2006. Precalibration evaluation procedures for mid-infrared milk analyzers. J. Dairy Sci. 89:2761-2774.

Lynch, J. M., A. L. Lock, D. A. Dwyer, R. Noorbakhsh, D. M. Barbano, and D. E. Bauman. 2005. Flavor and stability of pasteurized milk with elevated levels of conjugated linoleic acid and vaccenic acid. J. Dairy Sci. 88:489-498.

Ma, Y., D. M. Barbano, and M. Santos. 2003. Effect of $\mathrm{CO}_{2}$ addition to raw milk on proteolysis and lipolysis at $4^{\circ} \mathrm{C}$. J. Dairy Sci. $86: 1616-1631$.

Robertson, N. H., A. Dixon, J. H. Nowers, and D. P. S. Brink. 1981. The influence of lipolysis, $\mathrm{pH}$ and homogenization on infra-red readings for fat, protein and lactose. S. Afr. J. Dairy Technol. $13: 3-7$.

Sjaunja, L.-O. 1984. Studies on milk analyses of individual cow milk samples. II. Factors affecting milk analyses by infrared techniques under laboratory conditions. Acta Agric. Scand. 34:260-272.

Stegeman, G. A., R. J. Baer, D. J. Schingoethe, and D. P. Casper. 1991. Influence of milk fat higher in unsaturated fatty acids on the accuracy of milk fat analyses by the mid-infrared spectroscopic method. J. Food Prot. 54:890-893.

van de Voort, F. R., S. Kermasha, J. P. Smith, B. L. Mills, and K. F. Ng-Kwai-Hang. 1987. A study of the stability of record of performance milk samples for infrared milk analysis. J. Dairy Sci. 70:1515-1523.

van de Voort, F. R., J. Sedman, G. Emo, and A. A. Ismail. 1992. Assessment of Fourier transform infrared analysis of milk. J. AOAC 75:780-785. 